\title{
The Effect of Laurus nobilis on the Blood and Lenses Antioxidant Activity in Rabbit Under Fat-Enriched Diet
}

\author{
D. CASAMASSIMA ${ }^{1}$, F. CHIOSI ${ }^{2}$, F. VIZZARRI $^{1}$, M. PALAZZO ${ }^{1}$, C. COSTAGLIOLA $^{2}$ \\ ${ }^{1}$ Department of Agricultural, Environmental and Food Sciences, University of Molise, \\ Campobasso, Italy, ${ }^{2}$ Department of Medicine and Health Science, University of Molise, \\ Campobasso, Italy
}

Received June 15, 2016

Accepted October 3, 2016

On-line December 16, 2016

\section{Summary}

Fat-enriched diet is strongly associated with cataract development. Laurus nobilis shows antioxidant activity. Herein we evaluated the effect of Laurus nobilis oral administration on the blood and lenses antioxidant activity in rabbits under fat-enriched diet. Sixty rabbits divided into 4 groups were used. One group represented the control (N-CTR). The second group (P-CTR) fed a diet supplemented with $2.5 \%$ of pig fat; the third group (EXP1) received a diet supplemented with $2.5 \%$ of pig fat and $1 \mathrm{~g} / \mathrm{kg}$ of dried-bay leaves; the fourth group (EXP2) was treated with dried-bay leaves at the rate of $1 \mathrm{~g} / \mathrm{kg}$ of feed. At baseline and at the end of the study ( 56 days) the following blood parameters were determined: thiobarbituric acid reactive substances (TBARS), reactive oxygen metabolites (ROMs), total phenols, superoxide dismutase (SOD), oxygen radical absorbance capacity $\left(\mathrm{ORAC}_{\mathrm{pca}}\right)$, ferric ion reducing antioxidant power (FRAP), retinol and alfa-tocopherol. At the end of the follow-up, the eyes were enucleated and the antioxidant profile, such as total antioxidant activity (TAC), TBARS, retinol and alfa-tocopherol of lenses was evaluated. Plasma ROMs and TBARS levels were statistically lower in the groups receiving bay leaves integration. A significant increase of plasma retinol, FRAP and ORAC $C_{\text {pca }}$ levels was found in EXP1 and EXP2 groups, whereas plasma alfa-tocopherol resulted statistically higher only in EXP2 group. Bay leaves supplementation enhanced $\mathrm{TAC}$, retinol and alfa-tocopherol in rabbit lens, particularly in EXP2 group; whereas lenses TBARS levels significantly decreased in both treated groups. These findings demonstrate that Laurus nobilis oral administration exerts a protective effect on the risk of cataract development in rabbits under fat-enriched diet.

\section{Key words}

Bay leaves • Antioxidant $\bullet$ Lens $\bullet$ Cataract $\bullet$ Fat-enriched diet

\section{Corresponding author}

F. Vizzarri, Department of Agricultural, Environmental and Food Sciences, University of Molise, Campobasso, Italy. E-mail: francesco.vizzarri@unimol.it

\section{Introduction}

Oxidative stress plays a key role in the pathogenesis of cataract both in experimental animal models and humans (Nita and Grzybowski 2016). Reactive oxygen species (ROS) are normally produced in aerobic organisms; in fact oxidative stress can be minimized but cannot be eliminated. However, a certain level of ROS is necessary as mediators in several cellular processes and signaling networks (Mittler et al. 2011), i.e. cell signaling, cell adhesion, cellular immune response, apoptosis and cell survival (Zhu et al. 2012). When free radicals accumulate in the lens, the polyunsaturated fatty acids are easily oxidized, leading to the initiation of cataract. Malondialdehyde, one of the end products of lipid peroxidation, is itself toxic, due to its high cross-linking ability. Lens opacity was detected also in dyslipidemic patients (Heydari et al. 2012), with or without ischemic heart disease (Leino et al. 1992, Nucci and Mets 1990).

Since oxidative stress is a common trigger of many age related conditions, including cataract, dietary natural extract-based approach to delay the onset or the 
progression of cataract has been widely investigated (Libondi et al. 1991). However, in literature several findings on this topic are inconsistent, where no evidence was reported from dietary supplementation with antioxidant to prevent or slow the progression of cataract (Chiu and Taylor 2007, Mathew et al. 2012). Clinical evidences reported little benefit deriving from vitamin supplementation either in prevention of age-related cataract or in reducing its progression (Chiu and Taylor 2007, Milton et al. 2006). Diet rich in fruits, vegetables, fish, pulses and starchy foods may exert a protective role against cataractogenesis (Theodoropoulou et al. 2014), whereas a strong association with cataract development and ocular degenerative diseases was found with hypercholesterolemia, hypertriglyceridemia, high LDL (low density lipoprotein) cholesterol, high intake of saturated fat and high fasting glucose (Heydari et al. 2012).

Although the correlation between antioxidants intake and age-related cataract is not well comprehended, clinical evidence suggest that dietary total antioxidant capacity is inversely associated with the risk for age-related cataract (Mares 2015). Thus, it is possible that dietary changes and antioxidants intake may reduce the risk for age related cataract. Most of these antioxidants are reducing agents, such as polyphenols, that are able to interrupt the free radical based chain reactions. Plant phytochemicals have shown preventive activities in models of oxidative stress. Ellagic acid inhibited the formation of cataracts induced by selenite in Wistar rats (Sakthivel et al. 2008) and prevented alterations in lens proteins (Sakthivel et al. 2011). The polyphenols in Moringa oleifera also prevented cataract formation in selenite-treated rat pups (Sasikala et al. 2010).

Flavonoids, phenolic acids, carotenoids, vitamins and lactoferrin are natural antioxidant molecules with anti-cataract activity (Sunkireddya et al. 2013). In traditional societies, it is more acceptable, accessible and affordable to have antioxidant substances in indigenous, user friendly and user accessible forms than administer them as pills, drugs or capsules.

Laurus nobilis is an evergreen plant or small tree, belonging to the family of Lauraceae in the genus Laurus. It is thought to have origin in Asia Minor region, from where it distributed to all over the Mediterranean region and other parts of Asia. It grows in many warm regions of the world, particularly in Southern Europe and around the Mediterranean Sea area (Chmit et al. 2014). Laurus nobilis presented high levels of nutritional support due to the content of proteins, free sugars, organic acids, PUFA and tocopherols together with antioxidant activity, such as scavenging activity, reducing power and lipid peroxidation inhibition (Dias et al. 2014). Laurus nobilis leaves showed to improve insulin function in in vitro study, whereas in in vivo human-trial exhibited a significant decrease of fasting serum glucose, serum LDL cholesterol and triglycerides, together with an increase in HDL (high density lipoprotein) cholesterol, after the intake of 1 and $3 \mathrm{~g}$ per day (Khan et al. 2009).

These findings prompted us to verify whether the oral administration of bay meal dried-leaves is associated with increased anti-oxidant activity in blood plasma and lenses of rabbit fed a fat-enriched diet. To the best of our knowledge, the findings described herein represent the first report on the effect of Laurus nobilis on cataract prevention.

\section{Materials and Methods}

\section{Animals and diet}

The study lasted 56 days and was carried out on 60 New Zealand white male rabbits weaned at $35 \pm 2$ days and divided into 4 groups of 15 animals each, matched for age and body weight. The first group, negative control (N-CTR), received ad libitum a standard diet (Agrizoo, Miranda, Isernia, Italy); the second group, positive control (P-CTR) group, received a diet supplemented with $2.5 \%$ of pig fat; the third group (EXP1) fed a diet supplement with $2.5 \%$ of pig fat and $1 \mathrm{~g} / \mathrm{kg}$ of dried-bay leaves (Laurus nobilis); lastly, the fourth group (EXP2) received dried-bay leaves at the rate of $1 \mathrm{~g} / \mathrm{kg}$ in feed. Bay leaves were purchased by the Herboristeria Erbamea (San Giustino, Perugia, Italy). Rabbits were housed under conventional conditions and exposed to light-dark cycle of $12 \mathrm{~h}$ with free access to water and feed (daily recorded). All procedures were performed in accordance with the guidelines no. 86/609/EEC stipulated by Committee and the European Union Guidelines for animal experimentation. At the end of the experiment (day 56), animals were sacrificed by gas embolism, the eyes were quickly enucleated and the lenses were microscopically removed. The study was conducted in accordance with the Association for Research in Vision and Ophthalmology Statement for the Use of Animals in Ophthalmology and Vision Research.

\section{Blood collection}

At the beginning (day 0) and the end of the study 
(day 56), blood samples were collected from the vena auricularis marginalis, using a vacutainer method (Venoject, Terumo Europe N.V., Leuven, Belgium) with lithium-heparin tubes to produce plasma. Blood samples were centrifuged for $20 \mathrm{~min}$ at $3000 \mathrm{rpm}$ and the following plasma parameters were determined: thiobarbituric acid reactive substances (TBARS), reactive oxygen metabolites (ROMs), total phenols, superoxide dismutase (SOD), oxygen radical absorbance capacity $\left(\mathrm{ORAC}_{\mathrm{pca}}\right)$, ferric ion reducing antioxidant power (FRAP), retinol and alfa-tocoferol were performed. ROMs values were spectrophotometrically determined with the method of Cesarone et al. (1999), at a wavelength of $505 \mathrm{~nm}$ using a specific commercial kit (Diacron, Grosseto, Italy). Results were expressed in Carr units $\left(1 \mathrm{U} /\right.$ Carr corresponds to $0.024 \mathrm{mmol} / 1$ of $\left.\mathrm{H}_{2} \mathrm{O}_{2}\right)$. The determination of TBARS was performed according to the method of Esterbauer and Zollner (1989), using a standard curve with the 1,1,3,3 tetramethoxypropane (Sigma Aldrich, St. Louis, USA). Results were expressed in $\mu \mathrm{mol}$ of malondialdehyde (MDA) per 1 of plasma. Retinol and alfa-tocoferol were extracted from plasma samples with chloroform, according to the method of Zhao et al. (2004); results were expressed in $\mu \mathrm{g} / \mathrm{ml}$ of plasma. The determination of total phenols was done with the method of Folin-Ciocalteau reaction (Swain and Hills 1959), and results were expressed in $\mathrm{mg}$ of Trolox equivalents per $\mathrm{ml}$ of plasma $(\mathrm{mg} \mathrm{TE} / \mathrm{ml})$. SOD was determined using a colorimetric assay (Zhou and Prognon 2006); SOD activity was expressed in units per $\mathrm{mg}$ of protein $(\mathrm{U} / \mathrm{mg})$. ORAC $\mathrm{Oca}_{\mathrm{pca}}$ test was performed in accordance with the study of $\mathrm{Ou}$ et al. (2002); results were expressed in $\mu \mathrm{mol}$ of Trolox equivalents per 1 of plasma ( $\mu \mathrm{mol} \mathrm{TE} / \mathrm{l})$. FRAP test, expressed in $\mathrm{mmol} / \mathrm{ml}$, indicates the number of moles of ferric ion (FeIII) reduced to ferrous ion (FeII) from one mol of tested antioxidants (Benzie and Strain 1996).

\section{Preparation of lenses supernatant}

Two lenses of each rabbit, pooled together to give one sample, were washed with normal physiological saline solution and then processed. Each sample was homogenized for 60 " in equal volume of $50 \mathrm{mM}$ phosphate buffer ( $\mathrm{pH}$ 7.2) and centrifuged at $12,000 \times \mathrm{g}$ for $15 \mathrm{~min}$ at $4{ }^{\circ} \mathrm{C}$. The obtained supernatant was used for analysis.

\section{TBARS assay}

TBARS were determined in the lenses homogenates with the use of a spectrophotometric method based on the 2-thiobarbituric acid reaction. Sample was mixed with 2 volumes of cold $10 \%(\mathrm{w} / \mathrm{v})$ trichloroacetic acid (TCA) to precipitate protein. The pellet was removed, and an aliquot of the supernatant reacted with an equal volume of $0.67 \%(\mathrm{w} / \mathrm{v})$ thiobarbituric acid in a boiling water bath for $10 \mathrm{~min}$. After cooling, TBARS absorbance was detected at $532 \mathrm{~nm}$, using a spectrophotometer Varian Cary 100 UV-VIS (Varian, Australia). Results were expressed in $\mu \mathrm{mol} / \mathrm{g}$ eye wet weight.

\section{TAC assay}

The total antioxidant capacity (TAC) of lenses was measured on sample lenses supernatant by 2,2'-azinobis (3-ethylbenzothiazoline-6-sulfonate) (ABTS) radical cation decolorization assay, according to the method of Re et al. (1999). The $\mathrm{ABTS}^{+}$radical was generated by chemical reaction with potassium persulfate. For these propose, $25 \mathrm{ml}$ of ABTS $(7 \mathrm{mM})$ was spiked with $440 \mu \mathrm{l}$ of potassium persulfate $(140 \mathrm{mM})$ and allowed to stand in darkness at room temperature for $12-16 \mathrm{~h}$ (time required for the formation of the radical). Trolox was used as standard and the total antioxidant capacity of samples was defined as the concentration of Trolox having equivalent activity as $\mu \mathrm{mol} / \mathrm{g}$ eye wet weight.

\section{Alpha-tocopherol and retinol assay}

Alpha-tocopherol and retinol in lenses sample were determined using a procedure of Zhao et al. (2004) modified. Samples were analyzed by an HPLC system (Kontron Instruments, Milan, Italy) consisting of an autosampler (HPLC autosampler 360, Kontron Instruments, Milan, Italy) with a loop of $20 \mu$, a highpressure pump and a C18 column $5 \mu \mathrm{m}, 250 \times 4.60 \mathrm{~mm}$ (Phenomenex, Torrance, CA, USA). The mobile phase consisted of acetonitrile and methanol $(75: 25 \mathrm{v} / \mathrm{v})$, and a flow rate of $1 \mathrm{ml} \mathrm{min}^{-1}$ was used. Alpha-tocopherol and retinol were identified using a fluorimeter detector and comparing the samples retention time with the pure standards (97\%) purchased from Sigma Aldrich (St. Louis, USA). The quantification was carried out using the Geminyx system (version 1.91) comparing the area sample peak with that of the reference standards curve. Results were expressed as $\mu \mathrm{mol} / \mathrm{mg}$ of eye wet weight.

\section{Statistical analysis}

Statistical analyses were performed with SPSS 19 for Windows (2010). Blood parameters were assessed 
using repeated measures assay, including the dietary treatment as main effect between-groups (N-CTR, P-CTR, EXP1 and EXP2), while within-group the sampling time (Time) and dietary treatment $\mathrm{x}$ time (Diet $\mathrm{x}$ Time) was considered as main effect. Lenses were analyzed with one-way ANOVA test using the dietary treatment as independent variable. Post-hoc Tukey's t-test was used to compare the groups. Relationships between blood and lenses considered parameters were assessed by Pearson correlation coefficients. The results are presented as mean values and pooled standard error of mean (SEM). Differences were considered statistically significant at a level of $\mathrm{P}<0.05$.

\section{Results}

During the whole experiment the welfare and the body condition of animals was considered good and before sacrifice an ophthalmologist observed at a slit lamp lenses of in vivo animals and they were all normal and clear. At the end of the experiment, no effect due to the dietary treatment was recorded on the feed intake between the controls and experimental groups (average $137.48 \mathrm{~g} /$ day).

\section{Plasma oxidative parameters}

Plasma oxidative status is reported in Table 1. At the end of the follow-up ROMs levels were significantly lower $(\mathrm{p}<0.01)$ in EXP1 and EXP2 groups (280.1 vs. $193.0 \mathrm{U} / \mathrm{Carr}$, respectively) compared to those recorded in P-CTR group (352.7 U/Carr). Moreover, the difference of ROMs levels between EXP2 group and N-CTR was also significant (193.0 vs. 227.4 U/Carr, respectively). Bay leaves integration significantly reduced ROMs values in all treated groups (EXP1 and 2; $\mathrm{p}<0.01$ ), whereas in the fat diet enriched group the ROMs values were significantly increased (P-CTR 352.7 U/Carr, $\mathrm{p}<0.001)$.

TBARS values were found to be lower in the groups receiving bay leaves (EXP1, $2.83 \mu \mathrm{mol} / 1$; EXP2, $2.65 \mu \mathrm{mol} / 1 ; \mathrm{p}<0.05)$, compared to the control groups (N-CTR, $3.07 \mu \mathrm{mol} / 1$; P-CTR, $3.50 \mu \mathrm{mol} / 1$ ). In fact, EXP2 group showed the TBARS values lower than those recorded in control animals. TBARS values significantly increased in fat-enriched diet group without integration of bay leaves compared to controls.

A marked decrease of retinol levels $(p<0.01)$ was recorded in the P-CTR group $(0.191 \mu \mathrm{g} / \mathrm{ml})$. Bay leaves administration maintained the retinol levels within the normal range (EXP2, $0.316 \mu \mathrm{g} / \mathrm{ml})$. However, retinol values in groups receiving bay leaves supplementation were higher than those recorded in the control group (N-CTR, $0.262 \mu \mathrm{g} / \mathrm{ml}$ ).

Fat-enriched diet induced a significant diminution of plasma alfa-tocopherol levels (P-CTR, $2.01 \mu \mathrm{g} / \mathrm{ml}$; EXP1, $2.41 \mu \mathrm{g} / \mathrm{ml} ; \mathrm{p}<0.05)$. Bay leaves oral administration did not affect this parameter in the treated group (EXP2, 3.13 vs. N-CTR, $2.99 \mu \mathrm{g} / \mathrm{ml}$; not significant).

Total phenols showed a significant decrease secondary to fat-enriched diet (P-CTR, $58.3 \mathrm{mg} \mathrm{TE} / \mathrm{ml}$; $\mathrm{p}<0.05)$; Laurus nobilis administration counteracted the fat effects (EXP1, $62.8 \mathrm{mg} \mathrm{TE} / \mathrm{ml}$ ); in EXP2 group a significant increase of total phenols was recorded (75.1 mg TE/ml), compared to control (N-CTR, $62.7 \mathrm{mg}$ $\mathrm{TE} / \mathrm{ml} ; \mathrm{p}<0.05)$.

The plasma SOD values recorded at the end of the study showed a trend similar to the total phenols. In fact, plasma SOD content showed a decrease in the group fed a fat-enriched diet but not significant (P-CTR, $37.3 \mathrm{U} / \mathrm{mg}$; $\mathrm{p}>0.05)$; bay leaves administration attenuated the fat effects (EXP1, $42.3 \mathrm{U} / \mathrm{mg})$; in EXP2 group a significant increase of SOD values was recorded (61.3 U/mg), compared to control (N-CTR, $42.5 \mathrm{U} / \mathrm{mg}$; $\mathrm{p}<0.05)$.

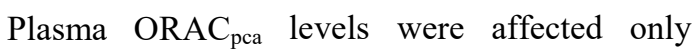
in the P-CTR group $(631.9 \mu \mathrm{mol}$ TE/l). Bay leaves administration maintained the ORAC levels within the normal range (EXP1, 788.4 $\mu \mathrm{mol}$ TE/l).

A marked decrease of FRAP levels was recorded in the P-CTR group $(383.7 \mathrm{mmol} / \mathrm{ml} ; \mathrm{p}<0.01)$. Bay leaves administration maintained the FRAP levels within the normal range (EXP2, $566.6 \mathrm{mmol} / \mathrm{ml})$.

For all parameters of plasma oxidative status a significant interaction effect between dietary supplementation and time (Diet $\mathrm{x}$ Time) was also recorded (Table 1).

\section{Antioxidant markers in rabbit lenses}

In Table 2 are summarized the TAC level recorded in rabbit lens. Animals fed a fat-enriched diet showed a significant decrease of this parameter compared to the negative control group. Contrarily, bay leaves administration increased the ability to counteract oxidative stress (EXP1, $146.69 \mu \mathrm{mol} \mathrm{TE} / \mathrm{g}$; EXP2, $160.02 \mu \mathrm{mol} \mathrm{TE} / \mathrm{g} ; \quad \mathrm{p}<0.001)$. The group receiving Laurus nobilis only exhibited TCA values statistically higher than those found in negative control group (N-CTR, $149.22 \mu \mathrm{mol} \mathrm{TE} / \mathrm{g} ; \mathrm{p}<0.001$ ). 
Table 1. Plasma oxidative status markers in rabbit.

\begin{tabular}{|c|c|c|c|c|c|c|c|c|c|}
\hline \multirow{2}{*}{ Parameters } & \multirow{2}{*}{$\begin{array}{l}\text { Time } \\
\text { (day) }\end{array}$} & \multicolumn{4}{|c|}{ Diet $^{\dagger}$} & \multirow{2}{*}{ SEM } & \multicolumn{3}{|c|}{ p-value } \\
\hline & & N-CTR & P-CTR & EXP1 & EXP2 & & Diet & Time & Diet x Time \\
\hline \multirow{2}{*}{ ROMs (U/Carr) } & 0 & $225.1^{\mathrm{a}}$ & $221.3^{\mathrm{a}}$ & $221.4^{\mathrm{a}}$ & $220.8^{\mathrm{a}}$ & 2.80 & & & \\
\hline & 56 & $227.4^{1, \mathrm{~b}}$ & $352.7^{2, \mathrm{~b}}$ & $280.1^{3, \mathrm{~b}}$ & $193.0^{4, \mathrm{~b}}$ & 13.99 & 0.001 & 0.001 & 0.001 \\
\hline \multirow{2}{*}{ TBARS $(\mu \mathrm{mol} / \mathrm{l})$} & 0 & 2.90 & $2.80^{\mathrm{a}}$ & 2.71 & 2.91 & 0.05 & & & \\
\hline & 56 & $3.07^{1}$ & $3.50^{2, \mathrm{~b}}$ & $2.831^{1,3}$ & $2.65^{3}$ & 0.09 & 0.001 & 0.015 & 0.001 \\
\hline \multirow{2}{*}{ Retinol $(\mu g / m l)$} & 0 & 0.266 & $0.277^{\mathrm{a}}$ & $0.300^{\mathrm{a}}$ & $0.276^{\mathrm{a}}$ & 0.01 & & & \\
\hline & 56 & $0.262^{1}$ & $0.191^{1, \mathrm{~b}}$ & $0.330^{2, \mathrm{~b}}$ & $0.316^{2, b}$ & 0.01 & 0.001 & 0.048 & 0.005 \\
\hline \multirow{2}{*}{ Alfa-tocopherol $(\mu \mathrm{g} / \mathrm{ml})$} & 0 & 3.11 & $2.88^{\mathrm{a}}$ & $3.07^{\mathrm{a}}$ & 3.05 & 0.03 & & & \\
\hline & 56 & $2.99^{1}$ & $2.01^{2, \mathrm{~b}}$ & $2.41^{2, \mathrm{~b}}$ & $3.13^{1}$ & 0.10 & 0.041 & 0.001 & 0.003 \\
\hline \multirow{2}{*}{ Total phenol (mg TE/ml) } & 0 & 63.1 & $66.2^{\mathrm{a}}$ & 63.7 & $64.8^{\mathrm{a}}$ & 0.52 & & & \\
\hline & 56 & $62.7^{1}$ & $58.3^{1, \mathrm{~b}}$ & $62.8^{1}$ & $75.1^{2, \mathrm{~b}}$ & 1.46 & 0.028 & 0.047 & 0.004 \\
\hline \multirow{2}{*}{$S O D(U / m g)$} & 0 & 41.4 & $42.7^{\mathrm{a}}$ & 40.9 & $41.8^{\mathrm{a}}$ & 0.73 & & & \\
\hline & 56 & $42.5^{1}$ & $37.3^{1, b}$ & $42.3^{1}$ & $61.3^{2, b}$ & 2.13 & 0.011 & 0.001 & 0.001 \\
\hline \multirow{2}{*}{$O R A C_{p c a}(\mu \mathrm{mol} T E / l)$} & 0 & 754.7 & $764.2^{\mathrm{a}}$ & 774.7 & 765.9 & 5.29 & & & \\
\hline & 56 & $755.9^{1}$ & $631.9^{2, \mathrm{~b}}$ & $788.4^{1}$ & $787.1^{1}$ & 15.07 & 0.001 & 0.001 & 0.011 \\
\hline \multirow{2}{*}{ FRAP $(\mathrm{mmol} / \mathrm{ml})$} & 0 & 582.1 & $591.6^{\mathrm{a}}$ & 583.2 & 587.8 & 1.84 & & & \\
\hline & 56 & $581.7^{1}$ & $383.7^{2, \mathrm{~b}}$ & $622.5^{3}$ & $566.6^{1}$ & 20.25 & 0.001 & 0.001 & 0.022 \\
\hline
\end{tabular}

Results are expressed as mean values and pooled SEM $(n=15) .{ }^{\dagger} \mathrm{N}-\mathrm{CTR}$, negative control group without fat integration; P-CTR, positive control group with pig-fat integration; EXP1, experimental group with pig-fat and meal dried-bay leaves integration; EXP2, experimental group with meal dried-bay leaves integration. 1,2,3,4 Different numbers within the same row indicate significant differences $(p<0.05)$. $a, b$ Different letters within the same column indicate significant differences $(p<0.05)$.

Table 2. Lens oxidative status markers in rabbit.

\begin{tabular}{lcccccc}
\hline \multirow{2}{*}{ Parameters } & \multicolumn{9}{c}{ Diet $^{\dagger}$} & \multirow{2}{*}{ SEM } & \multirow{2}{*}{ Diet } \\
\cline { 2 - 5 } & N-CTR & P-CTR & EXP1 & EXP2 & & \\
\hline \multirow{2}{*}{ TAC $(\mu \mathrm{mol} \mathrm{TE} / \mathrm{g})$} & $149.22^{1}$ & $106.78^{2}$ & $146.69^{1}$ & $160.02^{3}$ & 4.51 & 0.001 \\
TBARS $(\mu \mathrm{mol} / \mathrm{g})$ & $5.10^{1}$ & $6.58^{4}$ & $5.64^{1,2}$ & $4.87^{1,3}$ & 0.16 & 0.001 \\
Retinol $(\mu \mathrm{mol} / \mathrm{mg})$ & $37.93^{1}$ & $22.79^{2}$ & $23.53^{2}$ & $37.34^{1}$ & 1.68 & 0.001 \\
Alfa-tocopherol $(\mu \mathrm{mol} / \mathrm{mg})$ & $0.19^{1}$ & $0.08^{2}$ & $0.17^{1}$ & $0.20^{1}$ & 0.01 & 0.001 \\
\hline
\end{tabular}

Results are expressed as mean values and pooled SEM $(n=15) .{ }^{\dagger}$ N-CTR, negative control group without fat integration; P-CTR, positive control group with pig-fat integration; EXP1, experimental group with pig-fat and meal dried-bay leaves integration; EXP2, experimental group with meal dried-bay leaves integration. ${ }^{1,2,3,4}$ Different numbers within the same row indicate significant differences $(p<0.05)$.

TBARS levels markedly increased in both fatenriched diet groups (P-CTR, $6.58 \mu \mathrm{mol} / \mathrm{g} ; \mathrm{EXP1}$, $5.64 \mu \mathrm{mol} / \mathrm{g} ; \mathrm{p}<0.001)$ compared to the negative control group (N-CTR, $5.10 \mu \mathrm{mol} / \mathrm{g}$ ). Bay leaves administration significantly affected the TBARS levels in EXP1 group respect to P-CTR group.

Fat-enriched diet significantly reduced the retinol levels in both groups (P-CTR, $22.79 \mu \mathrm{mol} / \mathrm{mg}$; EXP1， $23.53 \mu \mathrm{mol} / \mathrm{mg} ; \quad \mathrm{p}<0.001)$. The bay leaves administration did not affect the retinol content both in EXP 1 and in EXP 2 groups (23.53 vs. $37.34 \mu \mathrm{mol} / \mathrm{mg}$; not significant).

Alpha-tocopherol levels were significantly affected in animals under a fat-enriched diet. P-CTR 
group showed a significant decrease of this parameter compared to the control values $(0.08$ vs. $0.19 \mu \mathrm{mol} / \mathrm{mg}$, respectively; $\mathrm{p}<0.001)$. Contrarily, bay leaves administration increased the alpha-tocopherol levels in EXP1 $(0.17 \mu \mathrm{mol} / \mathrm{mg})$, exhibiting a protective effect towards the diet induced lipid oxidation. Lastly, in the group receiving only Laurus nobilis, alfa-tocopherol content did not differ from the values recorded in control group ( 0.20 vs. $0.19 \mu \mathrm{mol} / \mathrm{mg}$, respectively; not significant).

Coefficient correlation analysis between the antioxidant parameters and the oxidative markers provided different results in blood and in lens. In particular, a positive and significant $(\mathrm{p}<0.05)$ correlation was found between the antioxidant lens parameters (TAC, alpha-tocopherol and retinol) and the antioxidant blood content $\left(\mathrm{ORAC}_{\mathrm{pca}}\right.$, FRAP, total phenol, alphatocopherol and SOD). Lens MDA levels were negatively correlated $(\mathrm{p}<0.001)$ with all the antioxidant markers tested, being positively correlated $(p<0.001)$ to blood ROMs values only. Antioxidant blood parameters

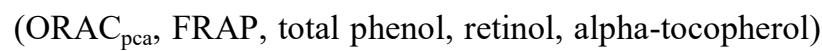
were negatively correlated $(\mathrm{p}<0.001)$ with blood ROMs and MDA values, whereas blood oxidative markers (ROMs and MDA) were positively correlated $(\mathrm{p}<0.001)$ between them. All correlations were performed on data collected at the end of the experiments.

\section{Discussion}

Our findings demonstrate that oral administration of bay leaves was associated with increased antioxidant activity in plasma and lenses of rabbit. Fraga (2003) reported that sesquiterpene lactones, extracted from bay leaves, exhibited a biological and pharmacological antioxidant activity on in vitro cultured cells. This finding was further confirmed by Elmastas et al. (2006), who suggested that the antioxidant activity exerted by bay leaves could be attributed to the ability of phenol compounds which act as donors of hydrogen, metal chelators and radical scavenger of peroxides and superoxides. This antioxidant effect delays the free radicals-induced proteins cross-linking and aggregation in the lens, events known to lead to cataract formation (Tan et al. 2008).

Laurus nobilis leaves represent a good source of antioxidant components that help to increase the overall antioxidant capacity of lens and protect it against lipid peroxidation induced by oxidative stress. Oral administration of Laurus nobilis leaves significantly increases retinol levels in the lens and decreases those of MDA, compared to the levels recorded in the fat-stress induced group. This effect could be due to its high carotenoid content (Yahyaa et al. 2015). Beta-carotene is a fat-soluble compound of the carotenoids, which are considered pro-vitamins, since they can be converted to active retinol. It is a strong antioxidant and is the best quencher of singlet oxygen. Contrary, when betacarotene, ascorbic acid, folic acid, iron, phytate and polyphenols levels are insufficient, oxidative stress in blood and lens increases (Tarwadi et al. 2008). The lowest MDA levels in the lens of treated animals, also confirms the protective effects against membrane lipid peroxidation exerted by Laurus nobilis intake. These findings agree with those reported by Gupta et al. (2010) who investigated the anti-cataracts effects of Trigonella foenum-graecum (Fenugreek) and found that the incidence of cataract in rats receiving fenugreek was lower than that observed in the untreated animals, by the inhibition of lipid peroxidation; biochemical parameters were modified according to the antioxidant property of the diet treatment. Also onions juice application, due to the high levels of flavonoids, counteracts cataract development in a model of selenite-induced cataract, as demonstrated by Javadzadeh et al. (2009). Lens GSH, SOD and GPX levels were higher in the onion-injected group than in the selenite-induced group, highlighting the additional support of bioactive compounds to the antioxidant agents. Curcumin significantly decreased the oxidative stress, responsible of cataract formation, in selenite-induced rat pups. These effects indicate that the consumption of curcumin in food can help to prevent the onset of cataract also in humans (Manikandan et al. 2010).

During the entire life, the lens is exposed to biochemical, physiological, and functional changes, as result of the natural process of aging. Senile cataract becomes progressively more severe and frequent in over50 -year-old people and represents the $48 \%$ of worldwide blindness. Protein damaging stress, fiber cell-membranes damage, deficit of glutathione, oxidative damage, calcium high level, abnormal lens epithelial cell migration, are several specific mechanisms responsible for senile cataract (Gupta et al. 2014). Surgery remains the only available treatment for cataract, and although all surgical procedures are effective for treatment, it is still under discussion the post-operative complications, the cost of surgery, and high number of people requiring surgery. 
However, the latter explained problems inspire researchers to find out alternative strategy for the treatment of cataract.

The lens has substantial supplies of antioxidant reserves, antioxidant enzymes and secondary defenses, to prevent cataract formation. The production of radical species is encouraged when eyes are exposed to environmental stress, such as UV light, smoking and oxygen, which damage lens proteins. Superoxide and hydroxyl radicals cause damage to cell membrane lipids and proteins, which deposit on the surface of the lens causing opacities.

Dietary antioxidants play an important role in helping endogenous antioxidant system for the neutralization of oxidative stress. Their deficiency is one of the causes of numerous chronic and degenerative pathologies. When the oxygen reactive species are in low or moderate concentrations, they are necessary for the maturation process of cellular structures and may act as tool for the host defense system. Since antioxidants block the oxidation process that produces free radicals, several evidences indicate that nutritional intervention may offer a way to diminish the risk of cataract (Mittler et al. 2011, Angelo et al. 2015).

Recently, Theodoropoulou et al. (2014), in a case-control study to assess the association between diet and risk of cataract in a Caucasian population, have found that cataract was positively associated with meat consumption and high intake of total fat, cholesterol and carbohydrates, whereas diet rich in fruits, vegetables, fish, pulses and starchy foods protect against cataract. On the other hand, Varma (2016) has ascertained that antioxidant nutrients are highly effective in inhibiting the formation of cataracts both in animals and in human epidemiological researches.

Laurus is a common component in European and North American dishes, such as soups, stews, meat, seafood and other vegetable dishes. Dried bay leaves have a pleasant odor, and its taste characteristically strong, pungent and aromatic greatly helps in digestion; in fact, it is used as a natural remedy in a wide range of digestive disorders. In high fat dishes its use as ingredient could reduce fat adsorption leading health benefits (Nurbas and Bal 2005).

In conclusion, the intake of bay leaves was associated with an improvement of blood and lenses antioxidant markers, highlighting a protective activity at the cellular level counteracting free radicals. These our findings suggest that the antioxidant activity of Laurus nobilis may exert a protective role on the risk of cataract development, secondary to a fat-enriched diet.

\section{Conflict of Interest}

There is no conflict of interest.

\section{Acknowledgements}

This work was supported by the research fund at the Department of Agricultural, Environmental and Food Sciences of the University of Molise, Campobasso. All co-authors carried out experiments in field and wrote the article.

\section{References}

ANGELO G, DRAKE VJ, FREI B: Efficacy of multivitamin/mineral supplementation to reduce chronic disease risk: a critical review of the evidence from observational studies and randomized controlled trials. Crit Rev Food Sci Nutr 55: 1968-1991, 2015.

BENZIE FF, STRAIN JJ: The ferric reducing ability of plasma (FRAP) as a measure of "antioxidant power": the FRAP assay. Anal Biochem 239: 70-76, 1996.

CESARONE MR, BELCARO G, CARATELli MA: Simple test to monitor oxidative stress. Int J Angiol 18: 127-130, 1999.

CHIU CJ, TAYLOR A: Nutritional antioxidants and age-related cataract and maculopathy. Exp Eye Res 84: 229-245, 2007.

CHMIT M, KANAAN H, HABIB J, ABBASS M, MCHEIK A, CHOKR A: Antibacterial and antibiofilm activities of polysaccharides, essential oil, and fatty oil extracted from Laurus nobilis growing in Lebanon. Asian Pac J Trop Med 7 (Suppl 1): S546-S552, 2014.

DIAS MI, BARROS L, DUEÑAS M, ALVES RC, OLIVEIRA MB, SANTOS-BUELGA C, FERREIRA IC: Nutritional and antioxidant contributions of Laurus nobilis L. leaves: would be more suitable a wild or a cultivated sample? Food Chem 156: 339-346, 2014. 
ELMASTAS M, GÜLÇIN İ, IŞıLDAK Ö, KÜFREVIOĞLU Öİ, İBAOĞLU K, ABOUL-ENEIN HY: Radical scavenging activity and antioxidant capacity of bay leaf extracts. J Iran Chem Soc 3: 258-266, 2006.

ESTERBAUER H, ZOLLNER H: Methods for determination of aldehydic lipid peroxidation products. Free Radical Bio Med 7: 197-203, 1989.

FRAGA B: Natural sesquiterpenoids. Nat Prod Rep 20: 392-413, 2003.

GUPTA SK, KALAISELVAN V, SRIVASTAVA S, SAXENA R, AGRAWAL SS: Trigonella foenum-graecum (Fenugreek) protects against selenite-induced oxidative stress in experimental cataractogenesis. Biol Trace Elem Res 1363: 258-268, 2010.

GUPTA VB, RAJAGOPALA M, RAVISHANKAR B: Etiopathogenesis of cataract: an appraisal. Indian J Ophthalmol 62: 103-110, 2014.

HEYDARI B, KAZEMI T, ZARBAN A, GHAHRAMANI S: Correlation of cataract with serum lipids, glucose and antioxidant activities: a case-control study. West Indian Med J 61: 230-234, 2012.

JAVADZADEH A, GHORBANIHAGHJO A, BONYADI S, RASHIDI MR, MESGARI M, RASHTCHIZADEH N, ARGANI H: Preventive effect of onion juice on selenite-induced experimental cataract. Indian J Ophthalmol 57: 185-189, 2009.

KHAN A, ZAMAN G, ANDERSON RA: Bay leaves improve glucose and lipid profile of people with type 2 diabetes. J Clin Biochem Nutr 44: 52-56, 2009.

LEINO M, PYÖRÄLÄ K, LEHTO S, RANTALA A: Lens opacity in patients with hypercholesterolemia and ischaemic heart disease. Electronic lens opacity measurements. Doc Ophthalmol 80: 309-315, 1992.

LiBONDI T, COSTAGLIOLA C, DELla CORTE M, FACCHIANO F, MENZIONE M, SAVASTANO S, SIMONELLI F, RINALDI E, AURICCHIO G: Cataract risk factors: blood level of antioxidative vitamins, reduced glutathione and malondialdehyde in cataractous patients. Metab Pediatr Syst Ophthalmol 14: 31-36, 1991.

MANIKANDAN R, THIAGARAJAN R, BEULAJA S, SUDHANDIRAN G, ARUMUGAM M: Effect of curcumin on selenite-induced cataractogenesis in Wistar rat pups. Curr Eye Res 35: 122-129, 2010.

MARES J: Food antioxidants to prevent cataract. JAMA 313: 1048-1049, 2015.

MATHEW MC, ERVIN AM, TAO J, DAVIS RM: Antioxidant vitamin supplementation for preventing and slowing the progression of age-related cataract. Cochrane Database Syst Rev 6: CD004567, 2012.

MILTON RC, SPERDUTO RD, CLEMONS TE, FERRIS FL: Centrum use and progression of age-related cataract in the Age-Related Eye Disease Study: a propensity score approach. AREDS report No. 21. Ophthalmology 113: 1264-1270, 2006.

MITTLER R, VANDERAUWERA S, SUZUKI N, MILLER G, TOGNETTI VB, VANDEPOELE K, GOLLERY M, SHULAEV V, VAN BREUSEGEM F: ROS signaling: the new wave? Trends Plant Sci 16: 300-309, 2011.

NITA M, GRZYBOWSKI A: The role of the reactive oxygen species and oxidative stress in the pathomechanism of the age-related ocular diseases and other pathologies of the anterior and posterior eye segments in adults. Oxid Med Cell Longev 2016: 3164734, 2016.

NUCCI P, METS MB: Cataract, hearing loss and hypercholesterolemia. Acta Ophthalmol (Copenh) 68: 739-742, 1990.

NURBAS M, BAL Y: Recovery of fixed and volatile oils from Laurus nobilis L. fruit and leaves by solvent extraction method. Eng Arch Fac EskişehirOsmangazi Univ 18: 2, 2005.

OU B, HUANG D, HAMPSCH-WOODILL M, FLANAGAN JA, DEEMER EK: Analysis of antioxidant activities of common vegetables employing oxygen radical absorbance capacity (ORAC) and ferric reducing antioxidant power (FRAP) assays: a comparative study. J Agr Food Chem 50: 3122-3128, 2002.

RE R, PELlEGRINI N, PROTEGGENTE A, PANNALA A, YANG M, RICE-EVANS CA: Antioxidant activity applying an improved ABTS radical cation decolorization assay. Free Radic Biol Med 26: 1231-1237, 1999.

SAKTHIVEL M, ELANCHEZHIAN R, RAMESH E, ISAI M, JESUDASAN CN, THOMAS PA, GERALDINE P: Prevention of selenite-induced cataractogenesis in Wistar rats by thepolyphenol, ellagic acid. Exp Eye Res 86: 251-259, 2008.

SAKTHIVEL M, GERALDINE P, THOMAS PA: Alterations in the lenticular protein profile in experimental seleniteinduced cataractogenesis and prevention by ellagic acid. Graefes Arch Clin Exp Ophthalmol 249: 1201-1210, 2011. 
SASIKALA V, ROOBAN BN, PRIYA SG, SAHASRANAMAM V, ABRAHAM A: Moringa oleifera prevents selenite-induced cataractogenesis in rat pups. J Ocul Pharmacol Ther 26: 441-447, 2010.

STATISTICAL PACKAGE FOR SOCIAL SCIENCE (SPSS): 18.0 Package Program. User's Guide, SPSS Inc. Chicago, IL, 2010.

SUNKIREDDYA P, JHAB SN, KANWARC JR, YADAVA SC: Natural antioxidant biomolecules promises future nano medicine based therapy for cataract. Colloids Surf B Biointerfaces 112: 554-562, 2013.

SWAIN T, HILLS WE: The phenolics constituents of Prunusdomestica I. The quantitative analysis of phenolics constituents. J Sci Food Agric 10: 63-69, 1959.

TAN AG, MITCHELL P, FLOOD VM, BURLUTSKY G, ROCHTCHINA E, CUMMING RG, WANG JJ: Antioxidant nutrient intake and the long-term incidence of age-related cataract: the Blue Mountains Eye Study. Am J Clin Nutr 87: 1899-1905, 2008.

TARWADI KV, CHIPLONKAR SA, AGTE V: Dietary and nutritional biomarkers of lens degeneration, oxidative stress and micronutrient inadequacies in Indian cataract patients. Clin Nutr 27: 464-472, 2008.

THEODOROPOULOU S, SAMOLI E, THEODOSSIADIS PG, PAPATHANASSIOU M, LAGIOU A, LAGIOU P, TZONOU A: Diet and cataract: a case-control study. Int Ophthalmol 34: 59-68, 2014.

VARMA SD: Effect of coffee (caffeine) against human cataract blindness. Clin Ophthalmol 10: 213-220, 2016.

YAHYAA M, BERIM A, ISAACSON T, MARZOUK S, BAR E, DAVIDOVICH-RIKANATI R, LEWINSOHN E, IBDAH M: Isolation and functional characterization of carotenoid cleavage dioxygenase-1 from Laurus nobilis L. (Bay Laurel) fruits. J Agric Food Chem 63: 8275-8282, 2015.

ZHAO B, THAM SY, LU J, LAI MH, LEE LKH, MOOCHHALA SM: Simultaneous determination of vitamins C, $\mathrm{E}$ and $\beta$ carotene in human plasma by high-performance liquid chromatography with photodiode-array detection. J Pharm Pharmac Sci 7: 200-204, 2004.

ZHOU JY, PROGNON P: Raw material enzymatic activity determination: a specific case for validation and comparison of analytical methods - the example of superoxide dismutase (SOD). J Pharm Biomed Anal 40: 1143-1148, 2006.

ZHU Y, PARK SH, OZDEN O, KIM HS, JIANG H, VASSILOPOULOS A, SPITZ DR, GIUS D: Exploring the electrostatic repulsion model in the role of Sirt3 in directing MnSOD acetylation status and enzymatic activity. Free Radic Biol Med 53: 828-833, 2012. 